\title{
A 2-week, polysomnographic, safety study of sodium oxybate in obstructive sleep apnea syndrome
}

\author{
Charles F. P. George • Neil Feldman • Yanping Zheng • \\ Teresa L. Steininger • Susanna M. Grzeschik • \\ Chinglin Lai $\cdot$ Neil Inhaber
}

Received: 12 August 2009/Revised: 13 November 2009/Accepted: 4 December 2009/Published online: 18 January 2010

(C) The Author(s) 2010. This article is published with open access at Springerlink.com

\begin{abstract}
Purpose Sodium oxybate (SXB) is approved for cataplexy and excessive daytime sleepiness in narcolepsy. Obstructive sleep apnea syndrome (OSAS) affects $\sim 9-50 \%$ of narcoleptics. Effects of 2-week SXB administration on apneahypopnea index (AHI), oxygen saturation $\left(\mathrm{SaO}_{2}\right)$, and sleep architecture were investigated in OSAS patients.

Methods OSAS patients $(n=48)$ received 2-week SXB or placebo (PBO) treatment with polysomnography at baseline
\end{abstract}

C. F. P. George $(\bowtie)$

University of Western Ontario, London Health Sciences Centre,

375 South Street,

London, ON N6A 4G5, Canada

e-mail: Charles.George@LHSC.ON.CA

\section{N. Feldman}

Clinical Research Group of St. Petersburg,

2525 Pasadena Avenue South,

St. Petersburg, FL 33707, USA

Y. Zheng $\cdot$ T. L. Steininger $\cdot$ S. M. Grzeschik $\cdot$ C. Lai $\cdot$ N. Inhaber Jazz Pharmaceuticals, Inc,

3180 Porter Drive,

Palo Alto, CA 94304, USA

\section{Present Address:}

Y. Zheng

Otsuka Pharmaceuticals,

100 Overlook Center, 1st Fl,

Princeton, NJ 08540, USA

Present Address:

S. M. Grzeschik

Genentech, Inc., 1 DNA Way,

South San Francisco, CA 94080-4990, USA

\section{Present Address:}

N. Inhaber

Novartis Pharmaceuticals Corporation,

East Hanover, NJ 07936, USA and day 14. The primary outcome measure was change from baseline in mean AHI. Secondary outcomes included changes from baseline in $\mathrm{SaO}_{2}$, and sleep architecture.

Results Compared with $\mathrm{PBO}, \mathrm{SXB}$ significantly increased reduction in mean AHI and obstructive apnea index with SXB $(-0.8 \pm 13.3$ vs. $-8.2 \pm 10.0 ; p=0.0327$ and $3.54 \pm 11.1$ vs. $-4.72 \pm 7.7 ; p=0.0054$, respectively) and significantly increased change in slow wave sleep duration (5.2 \pm $25.0 \mathrm{~min}$ vs. $29.4 \pm 37.0 \mathrm{~min} ; p=0.0038$ ). There were no differences between treatments in $\mathrm{SaO} 2$, central apneic events, or other measures. Adverse events, most commonly headache, were noted in nine of $27(33 \%)$ and six of 23 (26\%) patients receiving SXB and PBO, respectively. Conclusions Short-term use of $4.5 \mathrm{~g} / \mathrm{night}$ SXB did not generate respiratory depressant effects in OSAS patients as measured by AHI, obstructive apnea events, central apneas, and $\mathrm{SaO} 2$. Extended use of $\mathrm{SXB}$ in higher therapeutic doses in OSAS has not been studied, and merits caution.

Keywords Xyrem/sodium oxybate . Gamma-hydroxybutyrate/GHB · Sleep apnea ·

Polysomnography Slow wave sleep · Oxygen saturation

$\begin{array}{ll}\text { Abbreviations } \\ \text { AHI } & \text { Apnea-hypopnea index } \\ \text { AEs } & \text { Adverse events } \\ \text { CPAP } & \text { Continuous positive airway pressure } \\ \text { EDS } & \text { Excessive daytime sleepiness } \\ \text { ESS } & \text { Epworth Sleepiness Scale } \\ \text { GHB } & \text { Gamma-hydroxybutyrate } \\ \text { OSAS } & \text { Obstructive sleep apnea syndrome } \\ \text { PBO } & \text { Placebo } \\ \text { PSG } & \text { Polysomnography } \\ \mathrm{REM}^{2} & \text { Rapid-eye movement } \\ \mathrm{SaO}_{2} & \text { Oxygen saturation }\end{array}$




$\begin{array}{ll}\text { SDB } & \text { Sleep disordered breathing } \\ \text { SXB } & \text { Sodium oxybate } \\ \text { SXB/MOD } & \text { Sodium oxybate+modafinil } \\ \text { SWS } & \text { Slow wave sleep } \\ \text { ZOL } & \text { Zolpidem }\end{array}$

\section{Introduction}

Sodium oxybate (SXB), the sodium salt of gammahydroxybutyrate (GHB), was developed in France by Henri Laborit in 1960 and was initially used as an adjunct anesthetic agent $[1,2]$. Since then, it has been developed for the treatment of narcolepsy and is approved in the USA for the treatment of excessive daytime sleepiness and cataplexy in narcolepsy and for narcolepsy and cataplexy in the European Union and Canada. It is also approved in Germany for intravenous anesthesia and in Italy and Austria for the treatment of alcoholism. Reports of efficacy of SXB in the treatment of fibromyalgia [3] have led to development of a phase III program. The effects of SXB on sleep architecture [4-6] and improvement of cataplexy and excessive daytime sleepiness (EDS) in narcolepsy [7-10] are well documented; however, its precise mechanism of action remains unknown. The continuous improvement in cataplexy observed over 6-12 months of narcolepsy treatment suggests durable effects of SXB therapy that might be mediated via long-term neuroplastic changes [8].

There are conflicting reports on the effects of SXB on respiration during sleep. Studies with GHB have demonstrated significant central nervous system depression without respiratory depression [1, 11]; however, there have been reports of respiratory depression with GHB abuse often in the presence of cointoxicants such as alcohol [12], and respiratory depression was reported during clinical trials with SXB in narcolepsy $[4,13]$.

Although the incidence of co-occurring obstructive sleep apnea syndrome (OSAS) in narcolepsy patients has not been well studied, estimates range from 9-50\% [13-15]. The incidence of OSAS in narcolepsy may be related to an association between the high risk of OSAS with obesity [16-18], the higher body-mass-index found in narcoleptics compared with the general population, and binge-eating seen in childhood-onset narcolepsy [19, 20].

Significant concern regarding the effects of long-term use of SXB on sleep disordered breathing in narcoleptic patients with co-occurring OSAS remains despite no demonstrable acute effects of SXB on mean apnea-hypopnea index (AHI) or $\mathrm{SaO}_{2}$ [21]. In the continuation phase of the previously reported study [21], the effects of administration of an additional two weeks of outpatient SXB on AHI and other measures of sleep disordered breathing (SDB), sleep architecture, and EDS are described here.

\section{Methods}

Subjects

Sixty patients with OSAS were recruited from two centers (St. Petersburg, FL and London, Ontario, Canada). Inclusion criteria included a history of OSAS, AHI $\geq 10$ and $\leq 40$, and $\mathrm{SaO}_{2}$ nadir $\geq 75 \%$ (AASM Task Force 1999 criteria for OSAS [23]). Exclusion criteria included a recent history of substance abuse or shift work, or experiencing any major illness, including unstable cardiovascular, endocrine, neoplastic, gastrointestinal, hematologic, hepatic, immunologic, metabolic, neurological, pulmonary, and/or renal disease. Sixteen patients were using continuous positive airway pressure (CPAP) prior to screening and discontinued use during the study. Patients were withdrawn from the study if they failed to comply with the protocol or had any serious adverse events (AEs).

\section{Study design}

Following screening, patients had one baseline overnight polysomnography (PSG). This allowed the participants to acclimatize to the laboratory and ensured that the inclusion criteria were met. During this baseline PSG, ten patients experienced oxygen desaturation below $75 \%$ lasting less than $10 \mathrm{~s}$. These were judged by the investigators to be artifacts and the patients continued in the study. Prior to entering the 2-week randomized outpatient continuation phase reported here, patients received the following four treatments in a crossover design on four consecutive nights: (1) $9 \mathrm{~g} \mathrm{SXB}$, (2) $9 \mathrm{~g}$ sodium oxybate/modafinil $200 \mathrm{mg}$ (SXB/MOD), (3) Zolpidem $10 \mathrm{mg}$ (ZOL), and (4) placebo (PBO). These results are reported elsewhere [21].

Following the end of the acute phase, patients were randomized to one of two treatment groups: (1) SXB: Xyrem ${ }^{\circledR}$ $500 \mathrm{mg} / \mathrm{ml}$ oral solution, Jazz Pharmaceuticals, Inc. in a dose of $4.5 \mathrm{~g}$ per night for 13 days and $9 \mathrm{~g}$ for day 14 (taken in divided doses at bedtime and 2.5-4 $\mathrm{h}$ after their first dose) or (2) placebo (sodium citrate solution, equimolar to Xyrem ${ }^{\circledR}$ with respect to sodium and indistinguishable by taste, Jazz Pharmaceuticals, data on file), taken in divided doses at bedtime and 2.5-4 h after their first dose. A lower dose of SXB was administered in the outpatient setting ( $4.5 \mathrm{~g})$ due to the potential risk of respiratory depression in the unmonitored home setting. To provide a more relevant evaluation of potential SXB-induced risk, sleep breathing events and sleep architecture were studied using the highest approved dose of SXB $(9 \mathrm{~g})$ in subjects who had become accustomed to receiving a lower dose at home. Eight patients in each group used CPAP during the outpatient phase of the study and none used CPAP during the final PSG visit on day 14. The results for the patients who used CPAP were not analyzed separately. 
Data analysis

The primary outcome variable was the change in mean AHI from baseline to the final PSG visit on day 14. AHI was defined as the number of apneas (obstructive, mixed, and central) plus hypopneas per hour of sleep. Secondary outcomes included the mean changes in sleep architecture, oxygenation variables and Epworth Sleepiness Scale (ESS) scores [22]. Events were defined using standard criteria [23] and studies were manually scored by one registered polysomnographic technologist. Criteria for scoring hypopneas followed standard criteria of: (1) A clear decrease $(>50 \%)$ from baseline in the amplitude of a valid measure of breathing during sleep. Baseline is defined as the mean amplitude of stable breathing and oxygenation in the two minutes preceding onset of the event (in individuals who have a stable breathing pattern during sleep) or the mean amplitude of the three largest breaths in the 2 min preceding onset of the event (in individuals without a stable breathing pattern); (2) A clear amplitude reduction of a validated measure of breathing during sleep that does not reach the above criterion but is associated with either an oxygen desaturation of $>3 \%$ or an arousal; and (3) The event lasts $10 \mathrm{~s}$ or longer [23]. Sleep was scored per Rechtschaffen and Kales criteria [24]. The data were analyzed by the two-sample $t$ test. If the normality assumption was not met, Wilcoxon's rank-sum test was used. A significance level of 0.05 was used. All tests were two-sided. Due to the nonparametric nature of the data, Spearman's rank-order correlation coefficients were computed for changes in slow wave sleep (SWS; stages 3 and 4 nonrapid eye-movement sleep), AHI, and ESS. A correlation was accepted as significant if the $p$ value was $<0.05$; the sign of the correlation coefficient indicates whether the variable pairs positively or negatively correlated.
Ethics

The protocol used in this study was approved by the Institutional Review Board/Ethics Board of each participating trial center. Written informed consent was obtained from each patient prior to initiation of the study. This study was conducted in accordance with the Helsinki Declaration, revised 1997. Clinical trial registry: ClinicalTrials.gov; clinical trial registration number: NCT00086281.

\section{Results}

\section{Demographics}

Fifty patients $(83 \%)$ were randomized and $48(80 \%)$ completed the outpatient phase of the trial (Fig. 1). Two patients $(4 \%)$ withdrew due to adverse events prior to receiving any study drug. Demographic characteristics are presented for all randomized patients in Table 1. There were no differences between groups in mean age, weight, height, BMI, race, or sex. Results are presented for patients who completed the trial in Table 2 .

\section{Sleep disordered breathing}

There were no differences in respiratory PSG measurements between groups at baseline (see Table 1). The mean AHI was significantly reduced from baseline in the SXB treatment group compared with $\mathrm{PBO}$ at day $14(-8.2 \pm$ 10.0 vs. $-0.8 \pm 13.3 ; p=0.0327)$. In addition, the number of obstructive apneic events per hour (obstructive apnea index) was also significantly reduced from baseline in the SXB group compared with $\mathrm{PBO}(-4.72 \pm 7.68$ vs. $3.54 \pm$ 11.08; $p=0.0054)$. There were no differences between

Fig. 1 Subject flow diagram

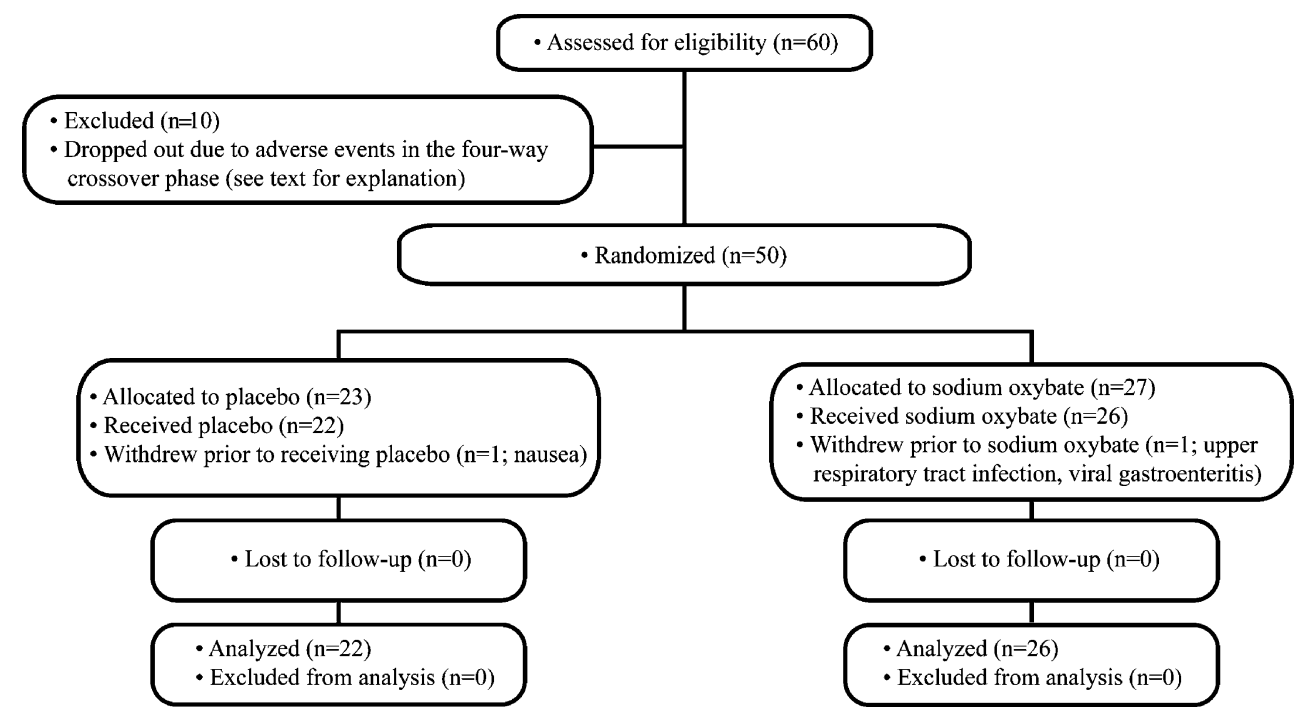


Table 1 Study demographics

\begin{tabular}{lcc}
\hline Characteristic & Placebo $(n=23)$, mean $(\mathrm{SD})$ & SXB $(n=27)$, mean $(\mathrm{SD})$ \\
\hline Age (years) & $49.7(11.1)$ & $49.7(8.0)$ \\
Weight $(\mathrm{kg})$ & $100.7(16.6)$ & $102.7(18.3)$ \\
Height $(\mathrm{cm})$ & $174.7(4.5)$ & $175.9(9.7)$ \\
BMI $\left(\mathrm{kg} / \mathrm{m}^{2}\right)$ & $33.0(5.4)$ & $33.2(5.0)$ \\
Race-counts $(\%)$ & & \\
Caucasian & $21(91.3)$ & $24(88.9)$ \\
Black & $1(4.3)$ & $2(7.4)$ \\
Asian & $1(4.3)$ & $0(0)$ \\
Hispanic & $0(0)$ & $1(3.7)$ \\
Other & $0(0)$ & $0(0)$ \\
Sex-counts $(\%)$ & & $21(77.8)$ \\
Male & $20(87)$ & $6(22.2)$ \\
Female & $3(13)$ & \\
\hline
\end{tabular}

treatment groups noted in $\mathrm{SaO} 2$ or central apneic events per hour. The proportion of patients at the final visit with an $\mathrm{AHI}<10$ for SXB was numerically greater than PBO $(2 / 22$ $(9.1 \%)$ vs. $8 / 26(30.8 \%))$ and opposite trend was seen for the proportion with $\mathrm{SaO}_{2}$ nadir $<85 \%$ for SXB compared with PBO (18/26 (69.2\%) vs. 12/22 (54.6\%); however, these differences were not statistically significant.

\section{Sleep architecture}

As shown in Table 1, there were no differences in sleep architecture characteristics between groups at baseline. There was an increased duration of SWS with SXB treatment, which was significantly greater than the change from baseline seen in PBO $(29.4 \pm 37.0 \mathrm{~min}$ vs. $5.2 \pm$ $25.0 \mathrm{~min} ; p=0.0038$ ). There were no differences between groups in incremental changes in time spent in stage 1 or stage 2 sleep, or rapid eye movement (REM) sleep, total sleep time, wake after sleep onset, or arousal index.

\section{Excessive daytime sleepiness}

Epworth sleepiness scale scores decreased in both treatment groups, but this difference was not significant $(-3.5 \pm 5.3$ with SXB vs. $-0.6 \pm 3.3$ with PBO; $p=0.09$ ).

\section{Correlational analysis}

As indicated in Fig. 2, the change from baseline in SWS was negatively and significantly correlated with the change from baseline in AHI for all patients $(r=-0.38 ; p=0.0074)$ but not for SXB $(r=-0.252, \mathrm{~ns})$ or PBO $(r=-0.274, \mathrm{~ns})$ alone. No significant correlations between change from baseline in SWS and either change in obstructive apneas or ESS were seen.
Safety

Of the 50 patients who were randomized and for whom AEs are reported in Table 3, two patients withdrew before receiving drug in this study. These two patients reported AEs at the end of the prior study which are reported elsewhere [21]. No other patients withdrew during the double-blind phase. As shown in Table 3, nine of 27 (33.0\%) and 6/23 (26.1\%) patients experienced AEs in the SXB and PBO groups, respectively. The most common individual event was headache $(4 / 23$ in $\mathrm{PBO}$ and $2 / 27$ in $\mathrm{SXB})$. There were no serious AEs or deaths reported during the study.

\section{Discussion}

There is a compelling clinical need to determine whether therapeutic agents with the potential to cause respiratory depression such as SXB can be safely used in patients with OSAS, especially since CPAP treatment compliance is generally poor, typically less than $50 \%$ in patients with OSAS [25]. SXB is currently a standard treatment for narcolepsy, where a potentially large proportion $(9-50 \%)$ of patients may also have diagnosed or undetected OSAS $[13,15,16]$. Patients with OSAS have compromised respiration during sleep due to an increased mechanical load on the airway combined with the normal decrease in respiratory drive. In normal subjects, reduced facilitatory drive to the upper respiratory muscles occurs as sleep progresses through deeper stages of sleep (stages 1-4) and then to REM. This reduced drive is accompanied by decreases in minute ventilation and ventilatory drive and lung volumes, leading to increased upper airway resistance and increased respiratory events [26]. 
Table 2 Treatment effects of SXB on SDB and sleep architecture

\begin{tabular}{|c|c|c|c|c|c|c|}
\hline & \multicolumn{3}{|l|}{ Baseline } & \multicolumn{3}{|l|}{ Night 14} \\
\hline & PBO $(n=22)$ & $\operatorname{SXB}(n=26)$ & $p$ value & PBO $(n=22)$ & $\mathrm{SXB}(n=26)$ & $p$ value \\
\hline \multicolumn{7}{|l|}{ Respiratory parameters - mean (SD) } \\
\hline AHI & $25.0(8.1)$ & $23.5(10.0)$ & NS & $24.2(13.9)$ & $15.3(8.5)$ & \\
\hline AHI Change from baseline & & & & $-0.79(13.3)$ & $-8.2(10.0)$ & 0.0327 \\
\hline Central Apneas Index & $0.55(1.34)$ & $0.68(1.84)$ & NS & $0.74(1.52)$ & $1.20(2.30)$ & \\
\hline Central Apneas Index Change from baseline & & & & $0.19(0.69)$ & $0.51(1.09)$ & NS \\
\hline Obstructive Apneas Index & $7.62(7.79)$ & $9.02(9.94)$ & NS & $11.16(10.72)$ & $4.30(4.40)$ & \\
\hline Obstructive Apneas Index Change from baseline & & & & $3.54(11.08)$ & $-4.72(7.68)$ & 0.0054 \\
\hline $\mathrm{SaO}_{2}(\mathrm{Mean})$ & $95.3(1.2)$ & $94.6(1.6)$ & NS & $94.9(1.5)$ & $94.6(1.6)$ & \\
\hline $\mathrm{SaO}_{2}$ (Mean) Change from baseline & & & & $-0.4(1.6)$ & $0.1(2.0)$ & NS \\
\hline $\mathrm{SaO}_{2}<90 \%$ (in min) & $1.0(1.2)$ & $1.5(2.2)$ & NS & $1.4(1.5)$ & $1.6(2.0)$ & \\
\hline $\mathrm{SaO}_{2}<90 \%$ (in min), change from baseline & & & & $0.5(1.5)$ & $0.1(2.7)$ & NS \\
\hline $\mathrm{SaO}_{2}<80 \%$ (in min) & $0.02(0.04)$ & $0.04(0.12)$ & NS & $0.2(0.6)$ & $0.1(0.3)$ & \\
\hline $\mathrm{SaO}_{2}<80 \%$ (in min) Change from baseline & & & & $0.2(0.6)$ & $0.1(0.3)$ & NS \\
\hline \multicolumn{7}{|l|}{ Sleep Architecture (min)-Mean (SD) } \\
\hline Stage 1 & $19.5(10.9)$ & $15.7(11.7)$ & NS & $10.2(6.5)$ & $8.7(8.4)$ & \\
\hline Stage 1 Change from baseline & & & & $-9.3(11.0)$ & $-7.0(12.0)$ & NS \\
\hline Stage 2 & $233.5(54.6)$ & $240.5(44.8)$ & NS & $254.8(55.2)$ & $265.6(34.5)$ & \\
\hline Stage 2 Change from baseline & & & & $21.3(43.3)$ & $25.1(52.4)$ & NS \\
\hline SWS (Stage 3\&4) & $37.5(25.4)$ & $43.7(19.8)$ & NS & $42.7(24.4)$ & $73.1(40.0)$ & \\
\hline SWS Change from baseline & & & & $5.2(25.0)$ & $29.4(37.0)$ & 0.0038 \\
\hline REM Sleep & $73.6(28.3)$ & $74.7(27.6)$ & NS & $84.2(28.8)$ & $71.3(30.4)$ & \\
\hline REM Sleep Change from baseline & & & & $10.6(26.0)$ & $-3.4(39.2)$ & NS \\
\hline WASO & $98.7(66.3)$ & $91.1(66.2)$ & NS & $80.8(58.3)$ & $56.8(25.5)$ & \\
\hline WASO Change from baseline & & & & $-18.0(49.3)$ & $-34.3(65.0)$ & NS \\
\hline TST & $364.2(65.8)$ & $374.7(65.5)$ & NS & $392.0(55.9)$ & $424.5(31.9)$ & \\
\hline TST Change from baseline & & & & $27.8(55.8)$ & $49.8(64.6)$ & NS \\
\hline Arousal index $(\mathrm{n} / \mathrm{hr})$ & $4.5(7.0)$ & $2.4(3.6)$ & NS & $4.9(10.3)$ & $1.5(2.7)$ & \\
\hline Arousal index Change from baseline & & & & $0.4(5.6)$ & $-0.8(4.2)$ & NS \\
\hline \multicolumn{7}{|l|}{ Epworth Sleepiness Score } \\
\hline ESS & $11(5.8)$ & $12.2(5.1)$ & NS & $10.5(6.6)$ & $8.6(4.8)$ & \\
\hline ESS Change from baseline & & & & $-0.6(3.3)$ & $-3.5(5.3)$ & NS \\
\hline
\end{tabular}

$\mathrm{SXB}=$ sodium oxybate; $\mathrm{PBO}=$ placebo; $\mathrm{AHI}=$ apnea-hypopnea index; $\mathrm{SaO} 2=$ oxygen saturation; $\mathrm{SWS}=$ slow wave sleep; $\mathrm{REM=rapid} \mathrm{eye}$ movement; WASO=wake after sleep onset; TST=total sleep time; ESS=Epworth Sleepiness Scale

This 2-week outpatient continuation phase of a trial of SXB in mild to moderate OSAS demonstrated that SXB $4.5 \mathrm{~g}$ in two divided doses nightly over 13 nights followed by a final night of $9 \mathrm{~g}$ challenge did not increase the risk of respiratory depression. Instead, compared with baseline PSG values obtained prior to the crossover phase of the study, an improvement in AHI and a reduction in the number of obstructive apnea events were seen at day 14 with $9 \mathrm{~g}$ SXB treatment. These results are similar to other trials of SXB which demonstrated a decrease in duration of obstructive apneas and increased SWS and no worsening of AHI in doses of approximately 4-9 g nightly [27-29].

Limitations of this study

Interpretation of these results are limited both by the small sample size $(n=50)$ and the analysis of only one final PSG night with SXB treatment. Although an overall decrease of AHI with SXB treatment was demonstrated, significant 
Fig. 2 Correlation analysis of SWS and AHI. The change from baseline in SWS was negatively correlated with the change from baseline in AHI for all patients $(r=-0.38$; $p=0.0074)$ but not for SXB $(r=-0.252, \mathrm{~ns})$ or PBO $(r=-0.274, \mathrm{~ns})$ alone

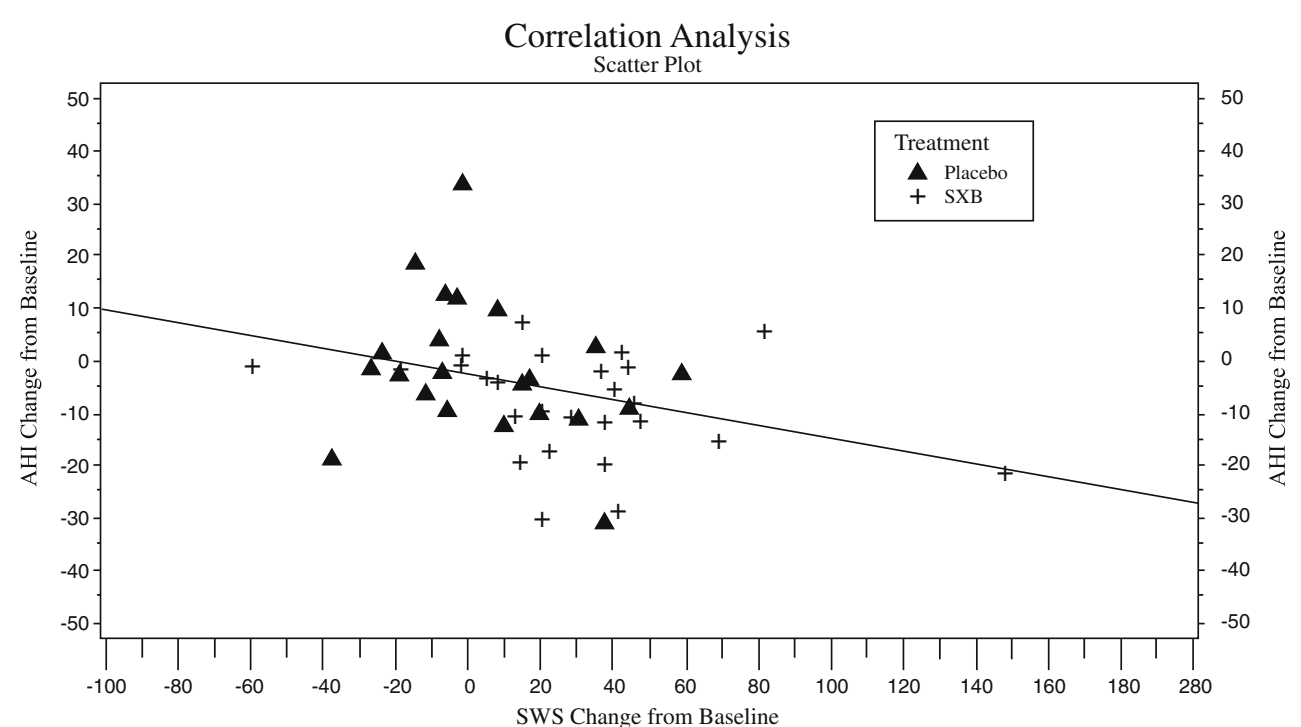

night-to-night variability in AHI has been noted in the literature [30-32]. Furthermore, the dosing scheme of SXB $9 \mathrm{~g}$ on the night of the final attended PSG and $4.5 \mathrm{~g}$ for 2 weeks at home was chosen to maximize patient safety but may not accurately reflect the long-term effects of SXB on sleep disordered breathing.

Methodological issues such as the choice of baseline PSG values prior to the crossover phase of the study instead
Table 3 Summary of treatment-related post-dose adverse events (MedDRA classification)

\begin{tabular}{|c|c|c|}
\hline System Organ Class Preferred term & $\begin{array}{l}\text { Placebo }(n=23) \\
\text { N }(\%)\end{array}$ & $\begin{array}{l}\text { Sodium oxybate }(\mathrm{n}=27) \\
\mathrm{N}(\%)\end{array}$ \\
\hline Number of patients with any event & $6(26.1)$ & $9(33.3)$ \\
\hline Eye disorders & $1(4.3)$ & $0(0)$ \\
\hline Asthenopia & $1(4.3)$ & $0(0)$ \\
\hline Eye pain & $1(4.3)$ & $0(0)$ \\
\hline Vision blurred & $0(0)$ & $1(3.7)$ \\
\hline Gastrointestinal disorders & $0(0)$ & $1(3.7)$ \\
\hline Dyspepsia & $0(0)$ & $1(3.7)$ \\
\hline Diarrhea & $0(0)$ & $1(3.7)$ \\
\hline General disorders and administration site conditions & $1(4.3)$ & $0(0)$ \\
\hline Fatigue & $1(4.3)$ & $0(0)$ \\
\hline Infections and infestations & $1(4.3)$ & $0(0)$ \\
\hline Bronchitis & $1(4.3)$ & $0(0)$ \\
\hline Injury, poisoning, and procedural complications & $0(0)$ & $1(3.7)$ \\
\hline Limb injury & $0(0)$ & $1(3.7)$ \\
\hline Musculoskeletal and connective tissue disorders & $1(4.3)$ & $1(3.7)$ \\
\hline Musculoskeletal stiffness & $1(4.3)$ & $0(0)$ \\
\hline Rotator cuff syndrome & $0(0)$ & $1(3.7)$ \\
\hline Nervous system disorders & $4(17.4)$ & $3(11.1)$ \\
\hline Dizziness & $0(0)$ & $1(3.7)$ \\
\hline Headache & $4(17.4)$ & $2(7.4)$ \\
\hline Somnolence & $1(4.3)$ & $0(0)$ \\
\hline Respiratory, thoracic, and mediastinal disorders & $2(8.7)$ & $1(3.7)$ \\
\hline Dry throat & $1(4.3)$ & $0(0)$ \\
\hline Epistaxis & $1(4.3)$ & $0(0)$ \\
\hline Pharyngolaryngeal pain & $0(0)$ & $1(3.7)$ \\
\hline Skin and subcutaneous disorders & $0(0)$ & $1(3.7)$ \\
\hline Pruritis generalized & $0(0)$ & $1(3.7)$ \\
\hline
\end{tabular}


of following the crossover phase may not accurately reflect the true baseline values. Also, the effects of SXB seen in the present study in OSAS patient may differ from those in narcoleptic patients with concurrent OSAS.

\section{Conclusion}

It is not clear how SXB might reduce AHI in OSAS patients. Overall, the change from baseline in mean SWS was associated with the change in mean AHI for the whole sample studied but not for the SXB or PBO group alone. This is most likely due to smaller numbers in the individual groups. It is not clear if the increment of SWS is mechanistically associated with improvement of AHI. It is speculated that SXB may affect brainstem catecholaminergic systems [33] that may increase the facilitatory drive to stabilize the upper airway. SXB may also have additional more direct effects on muscle tone, as GHB administrationinduced increased peripheral muscle EMG activity has been reported in animal studies [34].

The presence of sleep disordered breathing should be carefully evaluated in all patients who are candidates for SXB therapy. As indicated in the crossover study, nighttime administration of SXB $9 \mathrm{~g}$ resulted in more central apneas than PBO [21]. Therefore, further studies investigating the longer-term effects ( $>3$ months) of higher doses of SXB (6 to $9 \mathrm{~g}$ ) on sleep disordered breathing as well as studies investigating the respiratory effects of SXB on CPAP compliance and pressures in patients with co-occurring OSAS are recommended.

Short-term use of SXB at $4.5 \mathrm{~g}$ per night did not generate respiratory depressant effects in patients with OSAS as measured by AHI, obstructive apnea events, central apneas, and $\mathrm{SaO}_{2}$. The effects of longer term use of SXB in higher therapeutic doses for patients with OSAS have not been rigorously studied and nocturnal oximetry monitoring or nocturnal polysomnography with SXB might be useful. SXB therapy in patients with co-occurring OSAS should be approached with caution.

Acknowledgements This study was sponsored by Jazz Pharmaceutical, Inc., Palo Alto, CA and conducted by the authors. We wish to acknowledge assistance in data and statistical analysis by Howard Liang, MS. Dr. George participated in designing and conducting the study, as well as writing and editing the manuscript and independently analyzed the data. Dr. Feldman participated in designing and conducting the study, as well as editing the manuscript. Dr. Steininger, Grzeschik, and Inhaber, participated in writing and editing the manuscript. Dr. Lai takes responsibility for the integrity of the data and the accuracy of the data analysis and participated in editing the manuscript. Dr. Zheng provided methodologic and content expertise, and participated in writing and editing the manuscript.

Financial disclosures Charles F.P. George, MD, FRCPC, FCCP; support from Jazz Pharmaceuticals for the conduct of the Oxybate
SXB-23 Study. Susanna M. Grzeschik, PhD, RPh, Yanping Zheng, MD, Neil Inhaber, MD, FRCPC, FCCP and: (1) former employees of Jazz Pharmaceuticals, Inc.; (2) own stock in Jazz Pharmaceuticals, Inc. Chinglin Lai, PhD and Teresa L. Steininger, PhD: (1) employee of Jazz Pharmaceuticals, Inc.; (2) own stock options in Jazz Pharmaceuticals, Inc. Neil T. Feldman, MD: (1) support from Jazz Pharmaceuticals for the conduct of the Oxybate SXB-23 Study; (2) consultant and member of the speaker's bureau for Jazz Pharmaceuticals and Cephalon, Inc. (3) research support from sanofi-aventis.

Open Access This article is distributed under the terms of the Creative Commons Attribution Noncommercial License which permits any noncommercial use, distribution, and reproduction in any medium, provided the original author(s) and source are credited.

\section{References}

1. Laborit H (1964) Sodium 4-hydroxybutyrate. Int J Neuropharmacol 32:433-451

2. Vickers MD (1969) Gammahydroxybutyric acid. Int Anesthesiol Clin 7:75-89

3. Scharf MB, Baumann M, Berkowitz DV (2003) The effects of sodium oxybate on clinical symptoms and sleep patterns in patients with fibromyalgia. J Rheumatol 30:1070-1074

4. Mamelak M, Black J, Montplaisir J, Ristanovic R (2004) A pilot study on the effects of sodium oxybate on sleep architecture and daytime alertness in narcolepsy. Sleep 27:1327-1334

5. Scrima L, Hartman PG, Johnson FH Jr, Thomas EE, Hiller FC (1990) The effects of $\gamma$-hydroxybutyrate on the sleep of narcolepsy patients: a double-blind study. Sleep 3:479-490

6. Lammers GJ, Arends J, Declerck AC, Ferrari MD, Schouwink G, Troost J (1993) Gamma-hydroxybutyrate and narcolepsy: a double blind placebo controlled study. Sleep 16:216-220

7. US Xyrem ${ }^{\circledR}$ Multicenter Study Group (2002) A randomized, double blind, placebo-controlled multicenter trial comparing the effects of three doses of orally administered sodium oxybate with placebo for the treatment of narcolepsy. Sleep 25:42-49

8. US Xyrem ${ }^{\circledR}$ Multicenter Study Group (2003) A 12-month, openlabel, multi-center extension trial of orally administered sodium oxybate for the treatment of narcolepsy. Sleep 26:31-35

9. US Xyrem ${ }^{\circledR}$ Multicenter Study Group (2004) Sodium oxybate demonstrates long-term efficacy for the treatment of cataplexy in patients with narcolepsy. Sleep Med 5:119-123

10. Xyrem ${ }^{\circledR}$ International Study Group (2005) A double-blind, placebo-controlled, study demonstrates the nightly administration of sodium oxybate significantly improves excessive daytime sleepiness in narcolepsy patients taking concurrent stimulant medications. J Clin Sleep Med 1:391-397

11. Kleinschmidt S, Schellhase C, Mertzlufft F (1999) Continuous sedation during spinal anaesthesia: gamma-hydroxybutyrate vs. propofol. Eur J Anaesthesiol 16(1):23-30

12. Mason PE, Kerns WP II (2002) Gamma-hydroxybutyric acid intoxication. Acad Emerg Med 9:730-739

13. Xyrem ${ }^{\circledR}$ (sodium oxybate) oral solution Prescribing Information (2005) Jazz Pharmaceuticals, Inc., Palo Alto

14. Santamaria J, Sansa G, Iranzo A (2007) Prevalence and clinical relevance of sleep apnea in narcolepsy. Sleep 30(Suppl):A224 A225

15. Bonakis A, Howard RS, Kosky C, Williams A (2008) A severely sleep deprived patient. J Clin Sleep Med 4:378-380 
16. Young T, Palta M, Dempsey J, Skatrud J, Weber S, Badr S (1993) The occurrence of sleep-disordered breathing among middle-aged adults. N Engl J Med 328:1230-1235

17. Peppard PE, Young T, Palta M, Dempsey J, Skatrud J (2000) Longitudinal study of moderate weight change and sleepdisordered breathing. JAMA 284:3015-3021

18. Schwartz AR, Patil SP, Laffan AM, Polotsky V, Schneider H, Smith PL (2008) Obesity and obstructive sleep apnea: pathogenic mechanisms and therapeutic approaches. Proc Am Thorac Soc 5:185-192

19. Schuld A, Hebebrand J, Geller F, Pollmacher T (2000) Increased body-mass index in patients with narcolepsy. Lancet 355:1274-1275

20. Dahmen N, Bierbrauer J, Kasten M (2001) Increased prevalence of obesity in narcoleptic patients and relatives. Eur Arch Psychiatry Clin Neurosci 251:85-89

21. George CFP, Feldman N, Inhaber N, Steininger T, Grzeschik SG, Lai C, Zheng Y (2010) A Safety Trial of sodium oxybate in patients with obstructive sleep apnea: acute effects on sleepdisordered breathing. Sleep Med 11(1):38-42

22. Johns MW (1991) A new method for measuring daytime sleepiness: the Epworth sleepiness scale. Sleep 14:540-545

23. American Academy of Sleep Medicine Task Force (1999) Sleeprelated breathing disorders in adults: recommendations for syndrome definition and measurement techniques in clinical research. Sleep 22:667-689

24. Rechtschaffen A, Kales A (1968) A manual of standardized terminology, techniques and scoring system for sleep stages of human subjects. U.S. Public Health Service, U.S. Government Printing Office, Washington
25. Zozula R, Rosen R (2001) Compliance with continuous positive airway pressure therapy: assessing and improving treatment outcomes. Curr Opin Pulm Med 7:391-398

26. Kryger MH, Roth T, Dement W (2005) Principles and practice of sleep medicine, 4th edn. Saunders, Philadelphia, pp 232-244

27. Sériès F, Sériès I, Cormier Y (1992) Effects of enhancing slowwave sleep by gamma-hydroxybutyrate on obstructive sleep apnea. Am Rev Respir Dis 145:1378-1383

28. Black JE, Ristanovic R, Mamelak M, Montplaisir J (2002) Effect of increasing doses of sodium oxybate on nocturnal oxygen saturation: preliminary findings. Sleep 25(Suppl):A474A475

29. Ristanovic R, Black J, Mamelak M, Montplaisir J (2002) Analysis of dose effects of sodium oxybate on nocturnal respiratory disturbances. Sleep 25(Suppl):A473-A474

30. Aarab G, Lobbezoo F, Hamburger HL, Naeije M (2009) Variability in the apnea-hypopnea index and its consequences for diagnosis and therapy evaluation. Respiration 77(1):32-37

31. Bittencourt LR, Suchecki D, Tufik S, Peres C, Togeiro SM, Bagnato MC, Nery LE (2001) The variability of the apnoea-hypopnoea index. J Sleep Res 10(3):245-251

32. Wittig RM, Romaker A, Zorick FJ, Roehrs TA, Conway WA, Roth T (1984) Night-to-night consistency of apneas during sleep. Am Rev Respir Dis 129(2):244-246

33. Pardi D, Black J (2006) Gamma-hydroxybutyrate/sodium oxybate: neurobiology, and impact on sleep and wakefulness. CNS Drugs 20:993-1018

34. Godbout R, Pivik RT (1982) EEG and behavioral effects of gamma-hydroxybutyrate in the rabbit. Life Sci 31:739-748 